\title{
Ultimate Functional Preservation With Intersphincteric Resection for Rectal Cancer
}

\author{
Maxime Collard and Jérémie $H$. Lefevre *t \\ Sorbonne Université, Department of Digestive Surgery, AP-HP, Hôpital Saint Antoine, Paris, France
}

The proximity of the very low rectum rectal cancer to the anal sphincter raises a specific problem: how and until when can we preserve the anal continence without compromising the oncological result of the tumor resection? In this situation, intersphincteric resection

OPEN ACCESS

Edited by:

Des Winter,

St. Vincent's University

Hospital, Ireland

Reviewed by:

Hans De Wilt,

Radboud University Nijmegen Medical

Centre, Netherlands

Tsuyoshi Konishi,

Cancer Institute Hospital of Japanese

Foundation for Cancer

Research, Japan

Guilherme Pagin São Julião,

Angelita \& Joaquim Gama

Institute, Brazil

*Correspondence:

Jérémie H. Lefevre

jeremie.lefevre@aphp.fr

TORCID:

Jérémie H. Lefevre

orcid.org/0000-0001-7601-7464

Specialty section:

This article was submitted to

Surgical Oncology,

a section of the journal

Frontiers in Oncology

Received: 08 January 2020

Accepted: 20 February 2020

Published: 05 March 2020

Citation:

Collard M and Lefevre JH (2020) Ultimate Functional Preservation With

Intersphincteric Resection for Rectal

Cancer. Front. Oncol. 10:297.

doi: 10.3389/fonc.2020.00297
(ISR) offers an excellent alternative to abdominoperineal resection (APR), but the selection of patients for this option must be extremely precise. This complex choice justifies the simultaneous consideration of an oncological approach with a functional approach in order to provide a full benefit to the patient. When a circumferential resection margin of at least $1 \mathrm{~mm}$ can be performed with a distal resection margin of at least $1 \mathrm{~cm}$ with or without preoperative radiotherapy, ISR ensures a safety choice. The oncological results of ISR reported in the literature when performed properly found a 5-year disease-free survival of $80.2 \%$ with a local recurrence rate of only $5.8 \%$. In parallel to this oncological evaluation, the expected post-operative functional outcome and the resulting quality of life must be properly assessed pre-operatively, since partial or total resection of the internal sphincter impacts significantly on the functional outcome. Based on data from the literature, this work reports the essential anatomical considerations and then the oncological and functional elements indispensables when an anal continence preservation is evoked for a tumor of the very low rectum. Finally, the precise selection criteria and the major surgical principles are outlined in order to guarantee the safety of this modern choice for the patient.

Keywords: rectal cancer, intersphincteric resection (ISR), functional results, neoadjucant chemoradiation, LARS-low anterior resection syndrome

\section{INTRODUCTION}

The quality of rectal cancer surgery has improved considerably in recent years as a result of the emergence of key concepts such as the total mesorectal excision proposed by Heald et al. (1). These advanced have made it possible to standardize the surgical technique with the dual objective of guaranteeing both the best oncological result and the best functional result without a permanent stoma. This dual objective is particularly difficult for tumors of the very low rectum due to their proximity to the anal sphincter. The radical solution by abdomino-perineal resection (APR) was the historical choice option for these tumors, in particular to ensure the distal and lateral safety margin (2). However, the evolution of knowledge on minimum margins of safety and the discovery of intersphincteric resection (ISR) (3) have considerably reduced the place of APR in patients with very low rectal cancer (4). 
However, ISR indications are not a clear-cut issue. An overly extreme attitude toward ISR indications is dangerous because it may affect the oncological survival of patients on the one hand and lead to an unacceptable functional result on the other. The effectiveness of neoadjuvant radiochemotherapy makes patient selection even more complex. The objective of this work is therefore to take stock of the right indications of ISR in view of the data in the literature on the subject.

\section{INTERSPHINCTERIC RESECTION: ANATOMICAL CONSIDERATIONS}

Anatomical knowledge of the lower rectum and anal canal is an essential prerequisite for understanding the ISR problem (Figure 1). From a synthetic and practical point of view, the important anatomical points are:

- The low rectum is usually defined as the lower third of the rectum within $5-6 \mathrm{~cm}$ from the anal verge (5) or $2 \mathrm{~cm}$ above the dentate line. This distal part of the rectum can be identified as the rectal zone below the origin of the levator ani muscle where the mesorectum fuses with the rectosacral fascia and tapers at the anorectal ring. Other authors have defined the low rectum on MRI (magnetic resonance imaging) including all tumors with a lower tumoral edge below a line between the origin of the levator muscles and the pubic bone [(6); Figure 2].

- The anorectal ring corresponds to the U-shaped sling of striated muscle from the puborectalis muscle that pulls anteriorly the rectum and delimits the beginning of the surgical anal canal.

- The surgical anal canal extends from the anorectal ring to the anal verge and includes the external and internal sphincters. The anatomical anal canal is the distal part of the surgical anal canal and extends from the dental line to the anal verge. Histologically, it corresponds to the transitional epithelium.
- The length of the anal canal varies considerably from one individual to another. On average, the length of the surgical anal canal was $4.2 \mathrm{~cm}$ and that of the anatomical anal canal was $2.1 \mathrm{~cm}$ in a study dedicated to this question (7).

- The internal anal sphincter is formed by a very thickened segment of the circular muscle layer of the distal rectum. The external sphincter consists of skeletal muscle fibers that mix with the puborectal component of the levator ani to form a muscle ring. The space between internal and external sphincter constitutes the intersphincteric plane.

It is crucial to obtain a precise localization of the tumor in the lower rectum to be able to evaluate the appropriate surgical intervention to be proposed. In order to homogenize the discussion on tumors of the lower rectum, Rullier et al. proposed a four-stage classification [(8); Figure 3]. Type I low rectal cancers are supra-anal tumors, that is, lesions $>1 \mathrm{~cm}$ from the anorectal ring. Type II are juxta-anal tumors, that is, lesions $\leq 1 \mathrm{~cm}$ from the anorectal ring. Type III are intra-anal tumors, that is, lesions with internal anal sphincter invasion. Type IV are transanal tumors, that is, lesions with external anal sphincter or levator ani muscle invasion.

It is from the knowledge of these anatomical reminders and the classification of Rullier et al. that the place of ISR can be correctly investigated. In practice, ISR concerns stage II and III lesions. Some authors have assessed for stage IV tumors to propose ISR combined with partial resection of the external sphincter $(9,10)$.

In total, there are four types of ISR for lower rectal lesions stage II/III and some stage IV lesions that have been proposed in the literature [(9); Figure 4]:

- Partial ISR: Incision at the level of the dentate line or just below, removing one-third or half of the internal sphincter.

- Subtotal ISR: Incision 1-2 cm below the dentate line, removing two third of the internal sphincter.

- Total ISR: Incision $2 \mathrm{~cm}$ below the dentate line, removing the entire internal sphincter.

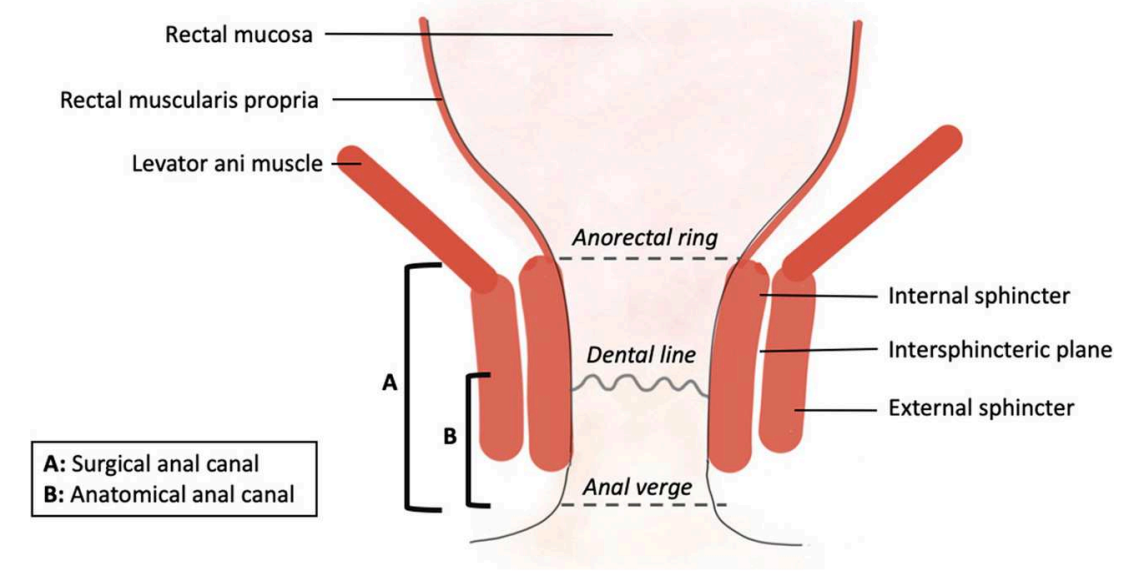

FIGURE 1 | Anatomy of the very low rectum. 


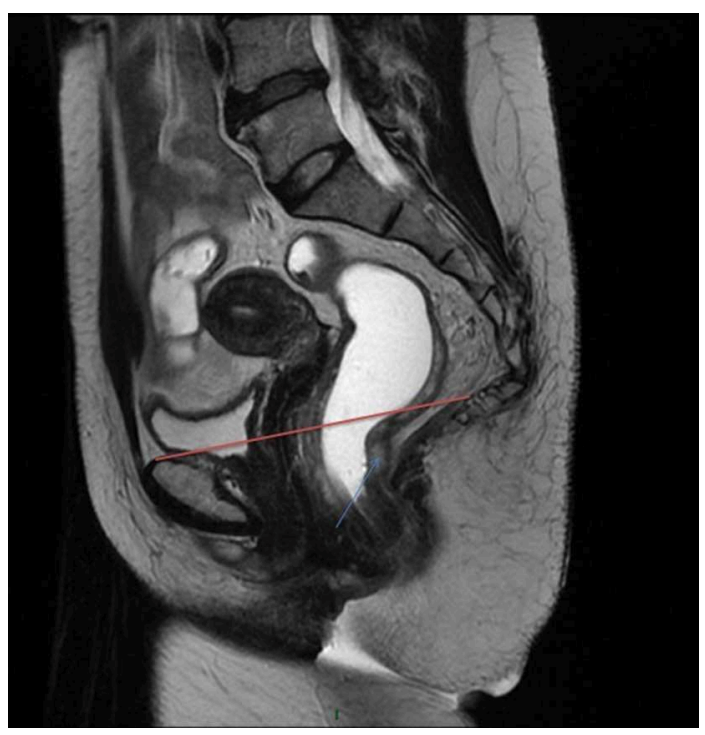

FIGURE 2 | Definition of the low rectum on MRI. On this sagittal view in a MRI T2 sequence, the low rectum begins below the red line the origin of the levator muscles and the pubic bone.

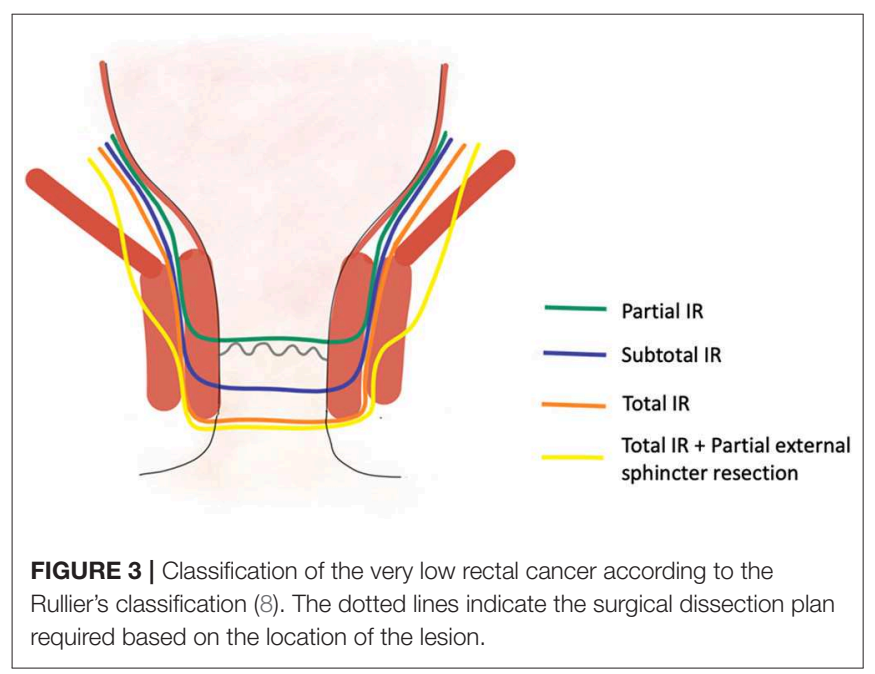

- Total ISR + Partial external sphincter resection: Incision $2 \mathrm{~cm}$ below the dentate line, removing the entire internal sphincter and removing partially the external sphincter.

The clinical use of these theoretical knowledges requires a correct classification of the lesion when ISR is being considered. It is therefore necessary to combine the examinations and converge the results to propose a precise classification of the tumor. Data from digital rectal examination, endoluminal ultrasound, and MRI are required to provide an efficient local staging (11). MRI is particularly effective in assessing the localization of the tumor, the invasion of internal and external sphincter and other adjacent structures such as the anus elevating muscle (12).

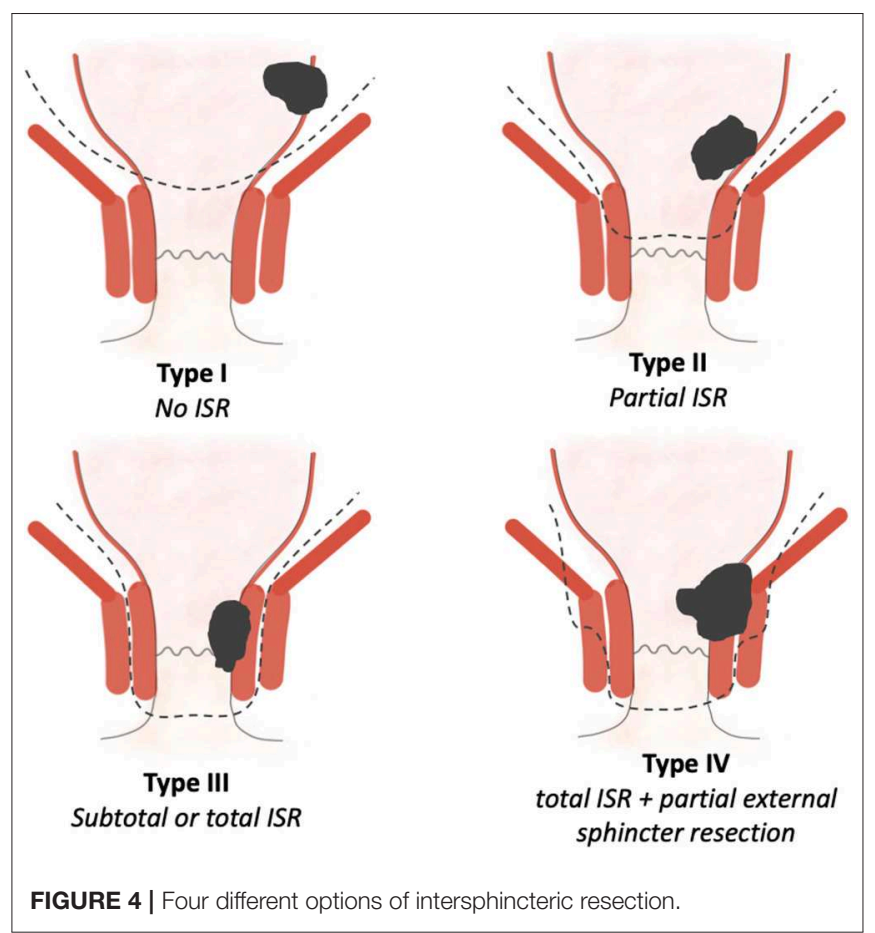

The rise of neoadjuvant treatments, particularly radiochemotherapy, makes the pre-operative assessment of lower rectal lesions even more complex. Indeed, it is particularly difficult to evaluate the tumor response on imaging and to differentiate fibrosis and persistent tumor. A recent metaanalysis reports a T-stage restaging accuracy of $52 \%$ for MRI and $65 \%$ for endoluminal ultrasound without significant difference between these two imaging modalities (13). In addition, this work highlights the high heterogeneity of studies on this subject, probably related to several factors such as variation in the delay between the radiotherapy and the imaging restaging, heterogeneity of imaging modalities (type of MRI sequence, 1.5 or 3 Tesla...) and finally a variable experience of the radiologist to interpret these complex exams (14).

Adding functional sequences to the MRI, could improve the performance in this regard. The perfusion sequences have been the subject of encouraging preliminary works, showing a satisfactory correlation between tumor response and tumor perfusion parameters (15), but this work has yet to be confirmed in larger studies. The diffusion sequences also make it possible to raise sensitivity to the evaluation of tumor response. It has been shown that the apparent diffusion coefficient was higher in tumors in response to radiochemotherapy than in nonreplying tumors (16). It would increase the distinction between tumor fibrosis and residual tumor. However, these data are very preliminary and reported only in small series.

All of these data underline that re-evaluation of tumor after radiochemotherapy, particularly in order to propose bowel continuity preservation by ISR that was not possible before neoadjuvant treatment, is a particularly challenging situation and requires a multidisciplinary discussion, including specialized radiologists. 


\section{ONCOLOGICAL APPROACH}

Oncological results of ISR reported in the literature found a 5year disease-free survival of $80.2 \%$ with a local recurrence rate of $5.8 \%$ (Table 1). More details about oncological results after ISR from different teams are presented in Table 1. The oncological challenge of ISR is to ensure safe circumferential and distal resection margins (CRM and DRM).

The CRM to be obtained is similar to that of standard proctectomy, i.e., CRM $>1 \mathrm{~mm}$ in order to avoid the risk of local recurrence (30) and of distant metastases (31). The specificity of ISR is the absence of mesorectum around the very low rectum. It is therefore important to be assured that the intersphincteric plane is not invaded by the tumor before proposing ISR with preservation of the external sphincter.

The DRM has its own specificities for patients eligible for ISR. Because of the absence of mesorectum around the very low rectum, the risk of metastases in the mesorectum under the tumor is nil (32). So, the expected benefit of a clear DRM is only for tumor resection and not for mesorectal excision.

For years, it has been considered that a DRM $\geq 5 \mathrm{~cm}$ was necessary to optimize the oncological result (33). This $5 \mathrm{~cm}$ cutoff did not permit ISR for tumors of the very low rectum for which an APR was the only option.

Recent studies have found that a DRM of $2 \mathrm{~cm}$ (34) and also $1 \mathrm{~cm}$ does not alter the oncological prognosis with (35) or without preoperative radiotherapy (36). To go even further, some studies question the value of a distal margin of $1 \mathrm{~cm}(37,38)$.

However, these results must be considered with great caution. Some studies focused on non-fixed specimens while others looked at fixed specimens (39). This technical detail is essential since a study dedicated to this question revealed on 26 specimens of colonic and rectal resection that $12-18 \mathrm{~h}$ after the fixation in formaldehyde the DRM was reduced by $57 \%$ compared to the DRM measured before fixation (40).
Interestingly, by considering the DRM as a continuous variable, Nash et al. reported that the extent of the DRM is significantly associated with disease-free survival in multivariate analysis independently of pre-operative radiotherapy (41). The relevant conclusion of this work relates the importance of guaranteeing a safety DRM in rectal surgery without being able to determine a precise cut-off. A Norwegian registry study involving 3,571 patients after proctectomy for rectal cancer found a negative impact on tumor recurrence when the DRM was $<10 \mathrm{~mm}$ (36). It is therefore reasonable to aim for a DRM $\geq 1 \mathrm{~cm}$ below the tumor when considering ISR. Since after fixation, this margin will decrease by more than $50 \%$, the objective of a margin of $1 \mathrm{~cm}$ for the surgeon will guarantee a margin $\geq 5 \mathrm{~mm}$ after fixation of the specimen. Interestingly, neoadjuvant treatments do not modify this cut-off (42).

This DRM of $1 \mathrm{~cm}$ leads on the one hand to propose an ISR for tumors located at $<1 \mathrm{~cm}$ from the anorectal ring and on the other hand to incise $1 \mathrm{~cm}$ under the tumor during surgical resection. Noteworthy, the DRM is not a criterion for excluding patients for ISR since this surgical technique allows the achievement a safe DRM in any tumor location as suggested by Rullier et al. (43).

As an overview of the resection margins, a CRM $>1 \mathrm{~mm}$ and a DRM $\geq 1 \mathrm{~cm}$ constitute the objectives. Since the resection cannot be laterally extended to the external sphincter (except in exceptional cases), invasion of the intersphincteric plane is a contraindication to ISR because CRM $\geq 1 \mathrm{~mm}$ cannot be performed. At the opposite, DRM is rarely a contraindication to surgery since it is almost always possible to incise $1 \mathrm{~cm}$ below the lesion during ISR.

The benefit of neoadjuvant treatments with radiotherapy or radiochemotherapy in lesions of very low rectum to increase the sphincter preservation rate is controversial in the literature. As reported in the review of the literature of Shirouzu et al. the rate of radiochemotherapy before ISR varied widely between each surgical team from 0 to $100 \%$ (44). It has not been possible to

TABLE 1 | Oncological outcomes after intersphincteric resection from studies including at least 100 patients.

\begin{tabular}{|c|c|c|c|c|c|c|c|}
\hline References & $n$ & $\begin{array}{l}\text { Median follow-up } \\
\text { (months) }\end{array}$ & $\mathrm{R} 0$ resection $(\%)$ & $\begin{array}{l}\text { Local } \\
\text { recurrence (\%) }\end{array}$ & $\begin{array}{c}\text { Distant } \\
\text { recurrence (\%) }\end{array}$ & $\begin{array}{l}\text { 5-year overall } \\
\text { survival (\%) }\end{array}$ & $\begin{array}{c}\text { 5-year disease-free } \\
\text { survival (\%) }\end{array}$ \\
\hline Bannon et al. (17) & 109 & 40 & - & 6.7 & 11 & 91 & 77 \\
\hline Schiessel et al. (18) & 121 & 94 & 96.7 & 5.3 & - & 88 & - \\
\hline Saito et al. (9) & 225 & 41 & 98.7 & 3.6 & 9 & 92 & 83 \\
\hline Portier et al. (19) & 173 & 67 & - & 8.6 & 17.6 & 86.1 & 83.9 \\
\hline Akasu et al. (20) & 120 & 42 & 96.7 & 6.7 & 13 & 91 & 77 \\
\hline Saito et al. (21) & 132 & 40 & 100 & 10.6 & 24 & 80 & 69 \\
\hline Laurent et al. (22) & 175 & 53 & 88 & 3.5 & 22.4 & 90 & 84 \\
\hline Akagi et al. (23) & 124 & 65 & - & 4.8 & 10.5 & - & - \\
\hline Lee et al. (24) & 163 & 53 & - & 11.0 & 20.2 & - & - \\
\hline Tsukamoto et al. (25) & 112 & 60 & 92.9 & - & - & - & 73.3 \\
\hline Rouanet et al. (26) & 400 & 49 & 96 & - & - & - & - \\
\hline Yamada et al. (27) & 107 & 41 & 100 & 2.5 & 20.5 & 92 & 87 \\
\hline Parks et al. (28) & 147 & 34 & 91.4 & 11.7 & 22.4 & - & - \\
\hline Kim et al. (29) & 488 & - & 98 & 2.5 & 15.8 & 86.7 & 80.7 \\
\hline Weighted mean & 2,596 & 52 & 96 & 5.8 & 16.7 & 88.2 & 80.2 \\
\hline
\end{tabular}


establish an increase in the chances of sphincter preservation thanks to neoadjuvant treatments (45-47). Nevertheless, these studies have often confused all rectal cancers without specifically considering very low rectal cancers. In addition, the doses of radiotherapy, whether or not combined with chemotherapy, and the delay between radiotherapy and surgery were variable. All these elements clearly biased the evaluation of radiotherapy in this context. In addition to the benefit of radiotherapy in rectal cancer on the survival when indicated (48), this treatment allows downstaging, downsizing of the lesion with $56 \%$ of patients with tumor regression grading 3-4 (49) and reducing tumor deposit, budding, and micrometastasis (50). Thus, when the CRM predicted on imaging is under $1 \mathrm{~mm}$, neoadjuvant radiochemotherapy is recommended to optimize the chances of oncologic survival with preservation of the sphincter (51).

In a systematic review of outcomes after ISR for low rectal cancer, summarizing 14 studies including 1,289 patients, overall 5 -year survival was $86 \%$ and disease-free 5 -year survival was $79 \%$. R0 resection was achieved in $97 \%$ of cases (52). In this systematic review, the administration of preoperative radiotherapy was highly variable between each study analyzed (from 0 to 100\%). Of course, it is difficult to compare survival after ISR with that of APR since ISR has been developed without any prospective randomized controlled trial. To control this evident bias of selection, a retrospective study used a propensity score matching to compare 112 patients after ISR to 173 patients after APR for very low rectal cancer without preoperative therapy (25). After propensity score matching, 5-year relapse-free survival rates were $69.9 \%$ for the ISR group and $67.9 \%$ for APR group $(p=0.64)$. Similarly, the 3-year cumulative local recurrence rate did not differ between the two groups (7.3\% in ISR group vs. 3.9\% in APR group, $p=0.10$ ). A recent study assessed the factors altering the disease-free survival after ISR in a cohort of 147 patients after preoperative chemoradiotherapy (28). On multivariate analysis, урТ stage, ymrT stage, and circumferential resection margin status were associated with worse disease-free survival.

To summarize, ISR is indicated for rectal tumor $<1 \mathrm{~cm}$ from the anorectal ring for which a CRM $\geq 1 \mathrm{~mm}$ can be guaranteed. Invasion of the external sphincter is therefore a contraindication.

\section{FUNCTIONAL APPROACH}

To obtain an overview of the anal function after an ISR, Martin et al. in their review of the literature found on average 2.7 bowel movements per $24 \mathrm{~h}, 51.2 \%$ of patients had a perfect continence, $29.1 \%$ of patients reported fecal soiling, $23.8 \%$ an incontinence to flatus, $18.6 \%$ an urgentury, and $18.4 \%$ took antidiarrheal medications (52). With a long-term follow-up, this functional results trend to improve over time (53).

The aim of the ISR as an ultimate strategy of sphincteric conservation is to avoid permanent colostomy. The benefit of avoiding permanent colostomy on the quality of life is controversial. A statistically higher quality of life thanks to sphincteric conservation has already been found (54), but this result was not confirmed by the meta-analysis from the Cochrane (55). This situation of sphincteric conservation by ISR exposes the patient to both the consequences of conventional proctectomy as the low anterior resection syndrome or urogenital lesions and to specific continence dysfunction because of the internal sphincter resection. Kupsch et al. have evaluated that $73 \%$ of patients described a low anterior rectal syndrome after ISR instead of $58 \%$ of patients after total mesorectal excision and $38 \%$ of patients after partial mesorectal excision (56). Bretagnol et al. disclosed a significant alteration of the continence in patients after ISR (Wexner score 10.8) vs. patients after conventional coloanal anastomosis (Wexner score 6.9) $(p<0.001)$, and an increase in antidiarrheal medication (57). But in this study the global quality of life was similar between these two groups. A more recent study observed the same comparison with a worse continence after ISR vs. conventional coloanal anastomosis evaluated by the Wexner Score but not reduction in the quality of life (58). Moreover, the risk of definitive stoma 10 years after sphincter-saving resection, for rectal cancer was $18 \%$ after partial ISR and 19\% after total ISR and these rates did not differ from the risk of a definitive stoma after a conventional coloanal anastomosis $(18 \%)(p=0.578)(59)$. In this study, the two independent risk factors for definitive stoma were age $>65$ years and surgical morbidity. Regarding specifically the consequences of surgical morbidity on the functional results, Yokota et al. showed that a major anastomotic leakage impact temporary the anal function that recovered over 2 years only in absence of anastomotic dehiscence (60). In this study, the development of an anastomotic dehiscence affected the functional result over after 2 years. In another work, anastomotic stricture as a delayed surgical complication impacted negatively the anal function (61).

Pre-operative radiochemotherapy represents an independent risk factor of continence dysfunction after ISR (61) and is associated with a lower colostomy-free survival (62).

The impact of the extent of sphincter resection on the functional result is controversial in the literature. Ito et al. did not find any association between the extent of excision of the internal sphincter and an alteration of the functional function (61). Even more surprisingly, Saito et al. did not observe an aggravation of the continence or of the quality of life between internal sphincter resection alone vs. internal sphincter resection with partial resection of external sphincter (63). A multicentric Japanese study did not report the same results as in this study analyzing 228 patients who underwent an ISR, patients with total intersphincteric resection displayed significantly worse continence than patients with partial or subtotal resection (9). In the same way, Denost et al. searched for risk factors for fecal incontinence after ISR and in the results of the multivariate analysis, the only independent predictors of good continence were distance of the tumor $>1 \mathrm{~cm}$ from the anorectal ring (OR, 5.88; 95\%CI [1.75-19.80]; $p=0.004)$ and anastomosis higher than $2 \mathrm{~cm}$ above the anal verge (OR, 6.59; 95\%CI [1.12-38.67]; $p=0.037)(53)$. These two factors are clearly correlated to the extent of the sphincteric resection.

Different types of anastomosis such as colonic J-Pouch have been evaluated in order to improve the functional results after a proctectomy (64). A recent randomized controlled trial did not find the superiority of a reservoir confection by colonic J-Pouch or side-to-end anastomosis and straight anastomosis on the anal 
function (65). This controversial issue was not evaluated in the specific setting of ISR but in conventional coloanal anastomosis. A reservoir is always performed when possible to maximize the chances of good functional result without increasing the risk of anastomotic leakage (66).

The last important point to be discussed is the impact of the pre-operative anal function that can be evaluated by anorectal manometry. This exam helps to understand the mechanisms of the continence troubles affected by ISR. The Maximum Resting Pressure (MPR) measured by anorectal manometry is mainly assured at $55 \%$ by the internal sphincter anal, although the external sphincter and the hemorrhoidal plexus contribute, respectively, at 30 and $15 \%$ for the MPR (67). So that, in a study assessing the performance of anorectal manometry before ISR in 68 patients, a high MPR (>60 mmHg) before surgery was independently associated with fecal incontinence after resection of the internal sphincter (68). In addition, a high-pressure zone $\leq 3 \mathrm{~cm}$ measured by preoperative highresolution anorectal manometry was the second risk factor of fecal incontinence after multivariable analysis. Interestingly, in comparison to subtotal/total ISR, patients after partial ISR had lower risk of fecal incontinence and had significantly a higher MPR and a higher maximum squeeze pressure post-operatively. Other exams have been evaluated as dynamic MRI. As this exam is poorly correlated to patient-reported symptom severity $(69,70)$, its place is restricted to patients with an externalized or suspected prolapse.

\section{PATIENT SELECTION}

Patient selection for ISR requires simultaneous consideration of the oncology and functional approaches outlined above. In summary, the ISR concerns lesions of the very low rectum located $<1 \mathrm{~cm}$ from the anorectal ring (type II) as well as lesions invading the internal sphincter but preserving the intersphincteric plane and the external sphincter (type III) (8). The choice between a partial, a subtotal or a total resection of the internal sphincter depends on the localization of the inferior edge of the tumor as a DRM of $1 \mathrm{~cm}$ should be obtained (71).

Some teams have considered the ISR with a partial resection of the external sphincter for tumors invading the external sphincter (type IV) $(9,72)$. In our point of view, the oncological safety is uncertain in this situation as the literature is very limited, restricted to few teams. The functional result is largely compromised by this extensive resection. So, in our center, the invasion of the external sphincter persistent after neoadjuvant radiochemotherapy is still an indication for an APR.

Many studies have explored the risk factors of a bad functional result after ISR underlining the importance of the preoperative function $(9,57-63,68,72)$. But, many different factors have been identified and differed significantly between all of these studies. So that, it is extremely difficult to predict the functional result efficiently when ISR is planned. Pre-operative anorectal manometry might bring some help but is not enough to be certain of the post-operative anal function (68). This exam is needed only if there is any doubt about a poor post-operative functional result. In addition, the quality of life is not perfectly correlated to the functional results (58). Thus, the predicted functional result must be cautiously evaluated before an ISR and though about with the patient. As many solutions exist when the anal function is altered, the decision of contraindicate an ISR only because of the predicted functional results should be well-considered. In daily practice, we avoid ISR only in patients with reported incontinence episodes. Denost et al. reported that with a step-up strategy face to a bad anal function with low fiber diet, bulking agents, glycerol-based enemas, loperamide, sphincter re-education by biofeedback, sacral nerve stimulation, and cecostomy for anterograde enema, only $5 \%$ of the patients need a definitive stoma formation due to major and refractory fecal incontinence in their experience (73).

Pre-operative radiotherapy deters the anal function (61) but allows downstaging and downsizing of the lesion (49) increasing the chances of a margin-free resection. In case of tumor invading the internal sphincter with a CRM $<$ $1 \mathrm{~mm}$, pre-operative radiochemotherapy is clearly justified as the functional considerations should not be deleterious to oncological considerations. Face to a less invasive tumors without an important invasion of the internal sphincter, the best strategy is more difficult as the it can be performed without neoadjuvant radiochemotherapy to improve the functional result but a local excision without ISR can be proposed after an efficient radiochemotherapy $(74,75)$. This dilemma applies only for tumors within the GRECCAR-2 criteria (i.e., tumor size $<4 \mathrm{~cm}$, mrT2-T3) (74). Advantages and drawbacks have to be evaluated in an experienced team and the preference of the patient should be integrated to the final decision. If a non-conservative approach is preferred for these T1/T2N0 lesions, no preoperative radiochemotherapy is required.

\section{SURGERY}

After a systematic bowel preparation (76), the surgical procedure can be started by abdominal approach or perineal approach first. As demonstrated by Kanso et al. a perineal approach first reduces operative time without increasing or reducing surgical morbidity, CRM, DRM overall and disease-free survival (77). Of course, with perineal approach first, exploration of the peritoneal cavity to find a peritoneal carcinomatosis is not possible. However, the risk of peritoneal carcinomatosis is rare in very low rectal cancer and is more infrequent than in upper rectal cancer (78). An important technical point to be considered is when the perineal dissection should be stopped. According to retrospective studies synthesized in a recent metaanalysis, transanal total mesorectal excision in comparison to laparoscopic total mesorectal excision significantly improved overall morbidity ( 34 vs. $41 \%, \mathrm{OR}=0.65,95 \% \mathrm{CI} 0.46-0.91$, $p=0.001$ ), major morbidity ( 8.7 vs. $14 \%$, OR $=0.53,95 \% \mathrm{CI}$ $0.34-0.83, p=0.005)$, anastomotic leak (6.4 vs. $11.6 \%$, OR $=$ $0.53,95 \%$ CI $0.31-0.93, p=0.03)$, and circumferential resection margin involvement ( 4 vs. $8.8 \%, \mathrm{OR}=0.48,95 \% \mathrm{CI} 0.27-0.86$, $p=0.01$ ) (79). Nevertheless, a recent analysis of the Norwegian national registry reveled an unexpected high rate of local 
recurrence after transanal total mesorecal excision (80). Because of this alarming result, the Norwegian Col-orectal Cancer Group recommended a temporary halt to the performance of transanal total mesorecal excision, and the Norwegian health authorities declared a national moratorium for this surgical approach of the rectal cancer until the national audit on is complete. Two prospective randomized controlled trials are ongoing $(81,82)$ and their results are indispensable to evaluate the oncological safety of the transanal total mesorectal excision and so to define when the perineal dissection should be stopped during perineal approach first for an ISR.

An important step that should not be forget is the insertion in the canal anal of a gauze with tumoricidal solution (betadine) and the closure of the distal rectum as soon as possible to reduce the risk of tumor-cell dissemination (71).

After resection of the surgical specimen, a handsewn coloanal anastomosis is made with a reservoir to maximize the chances of good functional result without increasing the risk of anastomotic leakage (83). In addition, a diverting loop is systematically performed.

The benefit of a systematic drainage after an ISR has not been specifically assessed but the GRECCAR-5 trial found that the

\section{REFERENCES}

1. Heald RJ, Moran BJ, Ryall RD, Sexton R, MacFarlane JK. Rectal cancer: the Basingstoke experience of total mesorectal excision, 1978-1997. Arch Surg. (1998) 133:894-9. doi: 10.1001/archsurg.133.8.894

2. Miles WE. The present position of the radical abdomino-perineal operation for cancer of the rectum in regard to mortality and post-operative recurrence. Proc R Soc Med. (1931) 24:989-91. doi: 10.1177/0035915731024 00764

3. Schiessel R, Karner-Hanusch J, Herbst F, Teleky B, Wunderlich M. Intersphincteric resection for low rectal tumours. Br J Surg. (1994) 81:13768. doi: 10.1002/bjs. 1800810944

4. Chau A, Maggiori L, Debove C, Kanso F, Hennequin C, Panis Y. Toward the end of abdominoperineal resection for rectal cancer? An 8-year experience in 189 consecutive patients with low rectal cancer. Ann Surg. (2014) 260:801-5; discussion 805-806. doi: 10.1097/SLA.0000000000000979

5. Salerno G, Sinnatamby C, Branagan G, Daniels IR, Heald RJ, Moran BJ. Defining the rectum: surgically, radiologically and anatomically. Colorectal Dis. (2006) 8(Suppl. 3):5-9. doi: 10.1111/j.1463-1318.2006.01062.x

6. Kusters M, Slater A, Betts M, Hompes R, Guy RJ, Jones OM, et al. The treatment of all MRI-defined low rectal cancers in a single expert centre over a 5-year period: is there room for improvement? Colorectal Dis. (2016) 18:O397-404. doi: 10.1111/codi.13409

7. Nivatvongs S, Stern HS, Fryd DS. The length of the anal canal. Dis Colon Rectum. (1981) 24:600-1. doi: 10.1007/BF02605754

8. Rullier E, Denost Q, Vendrely V, Rullier A, Laurent C. Low Rectal Cancer: Classification and Standardization of Surgery. Dis Colon Rectum. (2013) 56:560-7. doi: 10.1097/DCR.0b013e31827c4a8c

9. Saito N, Moriya Y, Shirouzu K, Maeda K, Mochizuki H, Koda K, et al. Intersphincteric resection in patients with very low rectal cancer: a review of the Japanese experience. Dis Colon Rectum. (2006) 49:S1322. doi: 10.1007/s10350-006-0598-y

10. Shelygin YA, Vorobiev GI, Pikunov DY, Markova EV, Djhanaev YA, Fomenko OY. Intersphincteric resection with partial removal of external anal sphincter for low rectal cancer. Acta Chir Iugosl. (2008) 55:4553. doi: 10.2298/ACI0803045S

11. Brown G, Davies S, Williams GT, Bourne MW, Newcombe RG, Radcliffe AG, et al. Effectiveness of preoperative staging in rectal cancer: digital rectal systematic use of a pelvic drain after rectal excision for rectal cancer did not confer any benefit to the patient (84). In our view, a systematic drainage is not justified after an ISR as in this situation the anastomosis in lower than other proctectomies so distant from an intra-abdominal drain.

\section{CONCLUSION}

Intersphincteric resection, when indicated, offers an interesting alternative to definitive terminal colostomy in case of very low rectal cancer. Thanks to a careful patient selection, this strategy is not just a compromise between quality of life and cancer treatment but represents an optimal oncological treatment for very low rectal cancer. Intersphincteric resection is a model of what surgery is expected to be in the twenty-first century: more and more effective on the disease, less and less damaging for the patient.

\section{AUTHOR CONTRIBUTIONS}

MC and JL writing, correction, and submission of the manuscript.

examination, endoluminal ultrasound or magnetic resonance imaging? $\mathrm{Br} J$ Cancer. (2004) 91:23-9. doi: 10.1038/sj.bjc.6601871

12. Holzer B, Urban M, Hölbling N, Feil W, Novi G, Hruby W, et al. Magnetic resonance imaging predicts sphincter invasion of low rectal cancer and influences selection of operation. Surgery. (2003) 133:65661. doi: $10.1067 / \mathrm{msy} .2003 .150$

13. Memon S, Lynch AC, Bressel M, Wise AG, Heriot AG. Systematic review and meta-analysis of the accuracy of MRI and endorectal ultrasound in the restaging and response assessment of rectal cancer following neoadjuvant therapy. Colorectal Dis. (2015) 17:748-61. doi: 10.1111/codi.12976

14. van der Paardt MP, Zagers MB, Beets-Tan RGH, Stoker J, Bipat S. Patients who undergo preoperative chemoradiotherapy for locally advanced rectal cancer restaged by using diagnostic MR imaging: a systematic review and meta-analysis. Radiology. (2013) 269:101-12. doi: 10.1148/radiol.13122833

15. Martens MH, Subhani S, Heijnen LA, Lambregts DMJ, Buijsen J, Maas $M$, et al. Can perfusion MRI predict response to preoperative treatment in rectal cancer? Radiother Oncol. (2015) 114:218-23. doi: 10.1016/j.radonc.2014.11.044

16. Monguzzi L, Ippolito D, Bernasconi DP, Trattenero C, Galimberti S, Sironi S. Locally advanced rectal cancer: value of ADC mapping in prediction of tumor response to radiochemotherapy. Eur J Radiol. (2013) 82:23440. doi: 10.1016/j.ejrad.2012.09.027

17. Bannon JP, Marks GJ, Mohiuddin M, Rakinic J, Jian NZ, Nagle D. Radical and local excisional methods of sphincter-sparing surgery after high-dose radiation for cancer of the distal $3 \mathrm{~cm}$ of the rectum. Ann Surg Oncol. (1995) 2:221-7. doi: 10.1007/BF02307027

18. Schiessel R, Novi G, Holzer B, Rosen HR, Renner K, Hölbling N, et al. Technique and long-term results of intersphincteric resection for low rectal cancer. Dis Colon Rectum. (2005) 48:1858-65; discussion 18651867. doi: 10.1007/s10350-005-0134-5

19. Portier G, Ghouti L, Kirzin S, Guimbaud R, Rives M, Lazorthes F. Oncological outcome of ultra-low coloanal anastomosis with and without intersphincteric resection for low rectal adenocarcinoma. Br J Surg. (2007) 94:341-5. doi: 10.1002/bjs.5621

20. Akasu T, Takawa M, Yamamoto S, Ishiguro S, Yamaguchi T, Fujita S, et al. Intersphincteric resection for very low rectal adenocarcinoma: univariate and multivariate analyses of risk factors for recurrence. Ann Surg Oncol. (2008) 15:2668-76. doi: 10.1245/s10434-008-0047-3 
21. Saito N, Sugito M, Ito M, Kobayashi A, Nishizawa Y, Yoneyama Y, et al. Oncologic outcome of intersphincteric resection for very low rectal cancer. World J Surg. (2009) 33:1750-6. doi: 10.1007/s00268-009-0079-2

22. Laurent C, Paumet T, Leblanc F, Denost Q, Rullier E. Intersphincteric resection for low rectal cancer: laparoscopic vs open surgery approach. Colorectal Dis. (2012) 14:35-41; discussion 42-43. doi: 10.1111/j.1463-1318.2010.02528.x

23. Akagi Y, Shirouzu K, Ogata Y, Kinugasa T. Oncologic outcomes of intersphincteric resection without preoperative chemoradiotherapy for very low rectal cancer. Surg Oncol. (2013) 22:144-9. doi: 10.1016/j.suronc.2013.03.003

24. Lee SY, Jo JS, Kim HJ, Kim CH, Kim YJ, Kim HR. Prognostic factors for low rectal cancer patients undergoing intersphincteric resection after neoadjuvant chemoradiation. J Surg Oncol. (2015) 111:1054-8. doi: 10.1002/jso.23932

25. Tsukamoto S, Miyake M, Shida D, Ochiai H, Yamada K, Kanemitsu Y. Intersphincteric resection has similar long-term oncologic outcomes compared with abdominoperineal resection for low rectal cancer without preoperative therapy: results of propensity score analyses. Dis Colon Rectum. (2018) 61:1035-42. doi: 10.1097/DCR.0000000000001155

26. Rouanet P, Bertrand MM, Jarlier M, Mourregot A, Traore D, Taoum $\mathrm{C}$, et al. Robotic versus laparoscopic total mesorectal excision for sphincter-saving surgery: results of a single-center series of 400 consecutive patients and perspectives. Ann Surg Oncol. (2018) 25:3572-9. doi: 10.1245/s10434-018-6738-5

27. Yamada K, Saiki Y, Takano S, Iwamoto K, Tanaka M, Fukunaga M, et al. Longterm results of intersphincteric resection for low rectal cancer in Japan. Surg Today. (2019) 49:275-85. doi: 10.1007/s00595-018-1754-4

28. Park JS, Park SY, Kim HJ, Cho SH, Kwak SG, Choi GS. Long-term oncologic outcomes after neoadjuvant chemoradiation followed by intersphincteric resection with coloanal anastomosis for locally advanced low rectal cancer. Dis Colon Rectum. (2019) 62:408-16. doi: 10.1097/DCR.0000000000001321

29. Kim JC, Lee JL, Bong JW, Seo JH, Kim CW, Park SH, et al. Oncological and anorectal functional outcomes of robot-assisted intersphincteric resection in lower rectal cancer, particularly the extent of sphincter resection and sphincter saving. Surg Endosc. (2019). doi: 10.1007/s00464-019-06989-3. [Epub ahead of print].

30. Park JS, Huh JW, Park YA, Cho YB, Yun SH, Kim HC, et al. A circumferential resection margin of $1 \mathrm{~mm}$ is a negative prognostic factor in rectal cancer patients with and without neoadjuvant chemoradiotherapy. Dis Colon Rectum. (2014) 57:933-40. doi: 10.1097/DCR.0000000000000171

31. Tilly C, Lefèvre JH, Svrcek M, Shields C, Fléjou JF, Tiret E, et al. R1 rectal resection: look up and don't look down. Ann Surg. (2014) 260:794800. doi: 10.1097/SLA.0000000000000988

32. Scott N, Jackson P, al-Jaberi T, Dixon MF, Quirke P, Finan PJ. Total mesorectal excision and local recurrence: a study of tumour spread in the mesorectum distal to rectal cancer. Br J Surg. (1995) 82:10313. doi: 10.1002/bjs. 1800820808

33. Goligher JC, Dukes CE, Bussey HJR. Local recurrences after sphincter saving excisions for carcinoma of the rectum and rectosigmoid. Br J Surg. (1951) 39:199-211. doi: 10.1002/bjs.18003915504

34. Pollett WG, Nicholls RJ. The relationship between the extent of distal clearance and survival and local recurrence rates after curative anterior resection for carcinoma of the rectum. Ann Surg. (1983) 198:15963. doi: 10.1097/00000658-198308000-00008

35. Ueno H, Mochizuki H, Hashiguchi Y, Ishikawa K, Fujimoto H, Shinto E, et al. Preoperative parameters expanding the indication of sphincter preserving surgery in patients with advanced low rectal cancer. Ann Surg. (2004) 239:3442. doi: 10.1097/01.sla.0000103070.13030.eb

36. Bernstein TE, Endreseth BH, Romundstad P, Wibe A, Norwegian Colorectal Cancer Registry. What is a safe distal resection margin in rectal cancer patients treated by low anterior resection without preoperative radiotherapy? Colorectal Dis. (2012) 14:e48-55. doi: 10.1111/j.1463-1318.2011.02759.x

37. Mezhir JJ, Shia J, Riedel E, Temple LK, Nash GM, Weiser MR, et al. Wholemount pathologic analysis of rectal cancer following neoadjuvant therapy: implications of margin status on long-term oncologic outcome. Ann Surg. (2012) 256:274-9. doi: 10.1097/SLA.0b013e31825c13d5

38. Rutkowski A, Nowacki MP, Chwalinski M, Oledzki J, Bednarczyk M, Liszka-Dalecki $\mathrm{P}$, et al. Acceptance of a $5-\mathrm{mm}$ distal bowel resection margin for rectal cancer: is it safe? Colorectal Dis. (2012) 14:718. doi: 10.1111/j.1463-1318.2010.02542.x

39. Park IJ, Kim JC. Adequate length of the distal resection margin in rectal cancer: from the oncological point of view. J Gastrointest Surg. (2010) 14:1331-7. doi: 10.1007/s11605-010-1165-3

40. Goldstein NS, Soman A, Sacksner J. Disparate surgical margin lengths of colorectal resection specimens between in vivo and in vitro measurements. The effects of surgical resection and formalin fixation on organ shrinkage. Am J Clin Pathol. (1999) 111:349-51. doi: 10.1093/ajcp/111.3.349

41. Nash GM, Weiss A, Dasgupta R, Gonen M, Guillem JG, Wong WD. Close distal margin and rectal cancer recurrence after sphincter-preserving rectal resection. Dis Colon Rectum. (2010) 53:1365-73. doi: 10.1007/DCR.0b013e3181f052d4

42. Trakarnsanga A, Gonen M, Shia J, Goodman KA, Nash GM, Temple LK, et al. What is the significance of the circumferential margin in locally advanced rectal cancer after neoadjuvant chemoradiotherapy? Ann Surg Oncol. (2013) 20:1179-84. doi: 10.1245/s10434-012-2722-7

43. Rullier E, Laurent C, Bretagnol F, Rullier A, Vendrely V, Zerbib F. SphincterSaving Resection for All Rectal Carcinomas. Ann Surg. (2005) 241:4659. doi: 10.1097/01.sla.0000154551.06768.e1

44. Shirouzu K, Murakami N, Akagi Y. Intersphincteric resection for very low rectal cancer: A review of the updated literature. Ann Gastroenterol Surg. (2017) 1:24-32. doi: 10.1002/ags3.12003

45. Bujko K, Kepka L, Michalski W, Nowacki MP. Does rectal cancer shrinkage induced by preoperative radio(chemo)therapy increase the likelihood of anterior resection? A systematic review of randomised trials. Radiother Oncol. (2006) 80:4-12. doi: 10.1016/j.radonc.2006.04.012

46. Baker B, Salameh H, Al-Salman M, Daoud F. How does preoperative radiotherapy affect the rate of sphincter-sparing surgery in rectal cancer? Surg Oncol. (2012) 21:e103-9. doi: 10.1016/j.suronc.2012.03.004

47. Gerard JP, Rostom Y, Gal J, Benchimol D, Ortholan C, Aschele C, et al. Can we increase the chance of sphincter saving surgery in rectal cancer with neoadjuvant treatments: lessons from a systematic review of recent randomized trials. Crit Rev Oncol Hematol. (2012) 81:218. doi: 10.1016/j.critrevonc.2011.02.001

48. Dahlberg M, Påhlman L, Bergström R, Glimelius B. Improved survival in patients with rectal cancer: a population-based register study. Br J Surg. (1998) 85:515-20. doi: 10.1046/j.1365-2168.1998.00603.x

49. Lefevre JH, Mineur L, Kotti S, Rullier E, Rouanet P, de Chaisemartin C, et al. Effect of interval (7 or 11 weeks) between neoadjuvant radiochemotherapy and surgery on complete pathologic response in rectal cancer: a multicenter, randomized, controlled trial (GRECCAR-6). J Clin Oncol. (2016) 34:377380. doi: 10.1200/JCO.2016.67.6049

50. Kinoshita H, Watanabe T, Yanagisawa A, Nagawa H, Kato Y, Muto T. Pathological changes of advanced lower-rectal cancer by preoperative radiotherapy. Hepatogastroenterology. (2004) 51:1362-66.

51. Gérard JP, André T, Bibeau F, Conroy T, Legoux JL, Portier G, et al. Rectal cancer: French Intergroup clinical practice guidelines for diagnosis, treatments and follow-up (SNFGE, FFCD, GERCOR, UNICANCER, SFCD, SFED, SFRO). Dig Liver Dis. (2017) 49:359-67. doi: 10.1016/j.dld.2017.01.152

52. Martin ST, Heneghan HM, Winter DC. Systematic review of outcomes after intersphincteric resection for low rectal cancer. Br J Surg. (2012) 99:60312. doi: $10.1002 /$ bjs. 8677

53. Denost Q, Laurent C, Capdepont M, Zerbib F, Rullier E. Risk factors for fecal incontinence after intersphincteric resection for rectal cancer. Dis Colon Rectum. (2011) 54:963-8. doi: 10.1097/DCR.0b013e31821d3677

54. Klose J, Tarantino I, Kulu Y, Bruckner T, Trefz S, Schmidt T, et al. Sphincterpreserving surgery for low rectal cancer: do we overshoot the mark? J Gastrointest Surg. (2017) 21:885-91. doi: 10.1007/s11605-016-3339-0

55. Pachler J, Wille-Jørgensen P. Quality of life after rectal resection for cancer, with or without permanent colostomy. Cochrane Database Syst Rev. (2012) 12:CD004323. doi: 10.1002/14651858.CD004323.pub4

56. Kupsch J, Jackisch T, Matzel KE, Zimmer J, Schreiber A, Sims A, et al. Outcome of bowel function following anterior resection for rectal cancer-an analysis using the low anterior resection syndrome (LARS) score. Int J Colorectal Dis. (2018) 33:787-98. doi: 10.1007/s00384-018-3006-x

57. Bretagnol F, Rullier E, Laurent C, Zerbib F, Gontier R, Saric J. Comparison of functional results and quality of life between intersphincteric resection and 
conventional coloanal anastomosis for low rectal cancer. Dis Colon Rectum. (2004) 47:832-8. doi: 10.1007/s10350-004-0523-1

58. Koyama M, Murata A, Sakamoto Y, Morohashi H, Takahashi S, Yoshida E, et al. Long-term clinical and functional results of intersphincteric resection for lower rectal cancer. Ann Surg Oncol. (2014) 21(Suppl. 3):S4228. doi: 10.1245/s10434-014-3573-1

59. Celerier B, Denost Q, Van Geluwe B, Pontallier A, Rullier E. The risk of definitive stoma formation at 10 years after low and ultralow anterior resection for rectal cancer. Colorectal Dis. (2016) 18:59-66. doi: 10.1111/codi.13124

60. Yokota M, Ito M, Nishizawa Y, Kobayashi A, Saito N. The impact of anastomotic leakage on anal function following intersphincteric resection. World J Surg. (2017) 41:2168-77. doi: 10.1007/s00268-017-3960-4

61. Ito M, Saito N, Sugito M, Kobayashi A, Nishizawa Y, Tsunoda Y. Analysis of clinical factors associated with anal function after intersphincteric resection for very low rectal cancer. Dis Colon Rectum. (2009) 52:6470. doi: 10.1007/DCR.0b013e31819739a0

62. Hassan I, Larson DW, Wolff BG, Cima RR, Chua HK, Hahnloser D, et al. Impact of pelvic radiotherapy on morbidity and durability of sphincter preservation after coloanal anastomosis for rectal cancers. Dis Colon Rectum. (2008) 51:32-7. doi: 10.1007/s10350-007-9099-x

63. Saito N, Ito M, Kobayashi A, Nishizawa Y, Kojima M, Nishizawa Y, et al. Longterm outcomes after intersphincteric resection for low-lying rectal cancer. Ann Surg Oncol. (2014) 21:3608-15. doi: 10.1245/s10434-014-3762-y

64. Hallböök O, Påhlman L, Krog $\mathrm{M}$, Wexner SD, Sjödahl R. Randomized comparison of straight and colonic $J$ pouch anastomosis after low anterior resection. Ann Surg. (1996) 224:58-65. doi: 10.1097/00000658-199607000-00009

65. Marti WR, Curti G, Wehrli H, Grieder F, Graf M, Gloor B, et al. Clinical outcome after rectal replacement with side-to-end, colon-j-pouch, or straight colorectal anastomosis following total mesorectal excision: a swiss prospective, randomized, multicenter trial (SAKK 40/04). Ann Surg. (2019) 269:827-35. doi: 10.1097/SLA.0000000000003057

66. Fazio VW, Zutshi M, Remzi FH, Parc Y, Ruppert R, Fürst A, et al. A randomized multicenter trial to compare long-term functional outcome, quality of life, and complications of surgical procedures for low rectal cancers. Ann Surg. (2007) 246:481-8; discussion 488-490. doi: 10.1097/SLA.0b013e3181485617

67. Penninckx F, Lestar B, Kerremans R. The internal anal sphincter: mechanisms of control and its role in maintaining anal continence. Baillieres Clin Gastroenterol. (1992) 6:193-214. doi: 10.1016/0950-3528(92)90027-C

68. Kitaguchi D, Nishizawa Y, Sasaki T, Tsukada Y, Ito M. Clinical benefit of high resolution anorectal manometry for the evaluation of anal function after intersphincteric resection. Colorectal Dis. (2019) 21:335341. doi: $10.1111 /$ codi.14528

69. Ramage L, Georgiou P, Qiu S, McLean P, Khan N, Kontnvounisios C, et al. Can we correlate pelvic floor dysfunction severity on MR defecography with patient-reported symptom severity? Updates Surg. (2018) 70:46776. doi: 10.1007/s13304-017-0506-0

70. Ramage L, Simillis C, Yen C, Lutterodt C, Qiu S, Tan E, et al. Magnetic resonance defecography versus clinical examination and fluoroscopy: a systematic review and meta-analysis. Tech Coloproctol. (2017) 21:91527. doi: 10.1007/s10151-017-1704-y

71. Chamlou R, Parc Y, Simon T, Bennis M, Dehni N, Parc R, et al. Long-term results of intersphincteric resection for low rectal cancer. Ann Surg. (2007) 246:916-21; discussion 921-922. doi: 10.1097/SLA.0b013e31815c29ff

72. Tokoro T, Okuno K, Hida J, Ueda K, Yoshifuji T, Daito K, et al. Analysis of the clinical factors associated with anal function after intersphincteric resection for very low rectal cancer. World J Surg Oncol. (2013) 11:24. doi: 10.1186/1477-7819-11-24
73. Denost Q, Rullier E. Intersphincteric Resection Pushing the Envelope for Sphincter Preservation. Clin Colon Rectal Surg. (2017) 30:36876. doi: $10.1055 / \mathrm{s}-0037-1606114$

74. Rullier E, Rouanet P, Tuech JJ, Valverde A, Lelong B, Rivoire M, et al. Organ preservation for rectal cancer (GRECCAR 2): a prospective, randomised, open-label, multicentre, phase 3 trial. Lancet. (2017) 390:46979. doi: 10.1016/S0140-6736(17)31056-5

75. Garcia-Aguilar J, Renfro LA, Chow OS, Shi Q, Carrero XW, Lynn PB, et al. Organ preservation for clinical T2N0 distal rectal cancer using neoadjuvant chemoradiotherapy and local excision (ACOSOG Z6041): results of an openlabel, single-arm, multi-institutional, phase 2 trial. Lancet Oncol. (2015) 16:1537-46. doi: 10.1016/S1470-2045(15)00215-6

76. Bretagnol F, Panis Y, Rullier E, Rouanet P, Berdah S, Dousset B, et al. Rectal cancer surgery with or without bowel preparation: The French GRECCAR III multicenter single-blinded randomized trial. Ann Surg. (2010) 252:8638. doi: 10.1097/SLA.0b013e3181fd8ea9

77. Kanso F, Maggiori L, Debove C, Chau A, Ferron M, Panis Y. Perineal or abdominal approach first during intersphincteric resection for low rectal cancer: which is the best strategy? Dis Colon Rectum. (2015) 58:63744. doi: 10.1097/DCR.0000000000000396

78. Maggiori L, Panis Y. The authors reply. Dis Colon Rectum. (2015) 58:e4589. doi: 10.1097/DCR.0000000000000485

79. Aubert M, Mege D, Panis Y. Total mesorectal excision for low and middle rectal cancer: laparoscopic versus transanal approach-a meta-analysis. Surg Endosc. (2019). doi: 10.1007/s00464-019-07160-8. [Epub ahead of print].

80. Larsen SG, Pfeffer F, Kørner H, on behalf of the Norwegian Colorectal Cancer Group. Norwegian moratorium on transanal total mesorectal excision. $\mathrm{Br} \mathrm{J}$ Surg. (2019) 106:1120-1. doi: 10.1002/bjs.11287

81. Lelong B, de Chaisemartin C, Meillat H, Cournier S, Boher JM, Genre D, et al. A multicentre randomised controlled trial to evaluate the efficacy, morbidity and functional outcome of endoscopic transanal proctectomy versus laparoscopic proctectomy for low-lying rectal cancer (ETAP-GRECCAR 11 TRIAL): rationale and design. BMC Cancer. (2017) 17:253. doi: 10.1186/s12885-017-3200-1

82. Deijen CL, Velthuis S, Tsai A, Mavroveli S, de Lange-de Klerk ESM, Sietses C, et al. COLOR III: a multicentre randomised clinical trial comparing transanal TME versus laparoscopic TME for mid and low rectal cancer. Surg Endosc. (2016) 30:3210-5. doi: 10.1007/s00464-015$4615-\mathrm{x}$

83. Pucciarelli S, Del Bianco P, Pace U, Bianco F, Restivo A, Maretto I, et al. Multicentre randomized clinical trial of colonic J pouch or straight stapled colorectal reconstruction after low anterior resection for rectal cancer. $\mathrm{Br} J$ Surg. (2019) 106:1147-1155. doi: 10.1002/bjs.11222

84. Denost Q, Rouanet P, Faucheron JL, Panis Y, Meunier B, Cotte E, et al. To drain or not to drain infraperitoneal anastomosis after rectal excision for cancer: the GRECCAR 5 randomized trial. Ann Surg. (2017) 265:47480. doi: 10.1097/SLA.0000000000001991

Conflict of Interest: The authors declare that the research was conducted in the absence of any commercial or financial relationships that could be construed as a potential conflict of interest.

Copyright (๑) 2020 Collard and Lefevre. This is an open-access article distributed under the terms of the Creative Commons Attribution License (CC BY). The use, distribution or reproduction in other forums is permitted, provided the original author(s) and the copyright owner(s) are credited and that the original publication in this journal is cited, in accordance with accepted academic practice. No use, distribution or reproduction is permitted which does not comply with these terms. 